\title{
Based on "Project Driven" of the Teaching Reform of the Single Chip Microcomputer Course
}

\author{
$\operatorname{Min} \mathrm{Ji}^{1, \text { a }}$ \\ ${ }^{1}$ Xijing University, \\ Shaanxi Xi'an ,China \\ aE-mail: 995010771@qq.com
}

\author{
Ning Wang ${ }^{3, c}$ \\ ${ }^{3}$ Xijing University, \\ Shaanxi Xi'an ,China \\ C E-mail: 2571449451@qq.com
}

\author{
Jingfeng $\mathrm{He}^{2, \mathrm{~b}}$ \\ ${ }^{2}$ Xijing University, \\ Shaanxi Xi'an ,China \\ bE-mail:573825625@qq.com
}

\author{
Chong Zhao ${ }^{4, d}$ \\ ${ }^{4}$ Xijing University, \\ Shaanxi Xi'an ,China \\ d E-mail: 36421157@qq.com
}

\begin{abstract}
This paper is based on the present situation and the needs of the country, and some innovation measures of cultivating graduate students are put forward. This paper analyzes the existing problems of the traditional teaching in vocational education from the status of SCM in teaching, and introduces the reform method of "project driven" teaching. This paper mainly introduces the characteristics of "project driven", the specific implementation method, through the "project" guide, inspire students thinking, improve students learning enthusiasm, and cultivate students' ability to think independently. Through the completion of specific "project" to cultivate students' ability and innovation consciousness.
\end{abstract}

Keywords-single chip microcomputer; project driven; reform; innovation; innovation consciousness

\section{INTRODUCTION}

With the rapid development of electronic technology, the design of the large scale integrated circuit and the further improvement of the manufacturing process, single chip microcomputer technology has been developed rapidly. SCM has been deeply infiltrated into every field of our daily life. SCM has been used as a basic course of control, and it has a very prominent core role. In order to improve the efficiency of vocational school students' learning efficiency and to adapt to the job requirements, it overcomes the traditional teaching mode focus on theoretical teaching, too abstract, practical teaching problems. Therefore, the teaching reform of single chip microcomputer based on "project driven" is put forward. The project driven teaching method is a kind of teaching method through the "project", which makes the teaching more attractive and practical value, and it is extended to teaching and educating people. Through the discussion of project teaching method in the integration of teaching practice is to pay attention to the skill training and practicing education system provides a new teaching method and teaching ideas, for vocational school students better and industry standards to provide the certain internship training opportunities, not only to promote the teachers' practical teaching ability, the teaching will not only to impart knowledge in books. At the same time, according to teaching project urge teachers, and it improves the teachers' ability of engineering practice.

As an important part of higher education,vocational education training occupy an important position for the community of high skills and applicable. Employmentoriented training direction established by vocational education raised new demands for education, including culture student have strong comprehensive vocational ability. SCM as a professional automation-related professional core courses, the teaching quality will directly affect student employment, and it score echnology will be widely used in industrial control field, importance self-evident. However, it hard to learn the MCU boring in traditional knowledge structure for students, so the MCU is daunting to student.

In the industrial automation system, industrial process control, process monitoring and lector mechanical integrated control, are all single microcontroller as the core or multi machine network system. With the rapid development of the hardware, software development language with the development of single-chip microcomputer has changed, single-chip microcomputer control system has realized the intelligent control, it improves the efficiency of system development and improve the quality of the products. Due to the single-chip microcomputer in volume, power consumption, price and performance, it has been widely used. Data measurement and control is one of the main direction of computer application, data acquisition, processing and control are the fields required core problem. While the temperature value in many control systems is an important index. Temperature index of some control situations sometimes requires accurate value multi-point real-time measurement. 


\section{THE SHORTAGE OF TRADITIONAL TEACHING}

The course of "single chip microcomputer principle and application", we are based on the syllabus of the traditional subject teaching method, based on the material, taking the teacher as the main body. Teacher talking and the students listening is as the main teaching methods. Textbook chapters in order for the teaching process, to talk about the introduction of single chip, hardware; retell instruction, statements, flow chart. Finally, teachers give some application examples. At the beginning of the students can be very serious, but because this course is a professional course, in front of a lot of the first order. As the previous theoretical knowledge is very abstract, this leads to the more confused and lost interest in learning. How to design teaching methods, stimulate students' learning interest, real understanding and mastering the SCM technology, is the need to solve the problem in the teaching of SCM.

"Single chip microcomputer principle and application" itself is a very practical course, if we only focus on the theory of teaching, and students' practical ability is too weak, like the cripples, students in the future in the job met practical problems, they will feel helpless.

In order to overcome the above drawbacks, we introduce the "project driven" teaching method.

\section{THE CHARACTERISTICS OF "PROJECT DRIVEN" TEACHING METHOD}

\section{A. S in teaching content}

In the past, the use of "knowledge" as a clue, but according to the students' ability to accept and demand, to "project" as a clue, to "sub project" as the module, the organization of teaching content, to meet the students' cognitive characteristics, in particular, the strong tune of knowledge and the times.

\section{B. in teaching method}

Emphasize the students' independent learning and exploration, emphasize the cultivation of students' selflearning ability. In the teaching process according to the demand of "project" to learn, also according to the characteristics of students' curiosity, and the teacher actively guide students, enable students to change their learning method, and change the passive learning to active learning, and change the concept of traditional student learning. By "learn" to "learn", it is the main task of university teaching. Teaching in universities is not traditional cramming method of teaching, and we must teach the students' autonomous learning.

\section{C. capacity development}

Focus on training students' innovative spirit and cooperation consciousness, students in the process of completing the project, will actively to think, explore. Everyone's ideas are not the same, teachers can guide them to carry on the discussion and the exchange, and appropriate to give comments and encouragement. So that they learn from each other, and can arouse the students' enthusiasm of the training their innovative spirit and cooperation consciousness.

Therefore, the "project teaching method" is a kind of teaching method which is based on the students' independent learning and teachers. It has broken the traditional teaching method of the teachers in accordance with the theoretical knowledge of the books. In the completion of the project, the process of training students' self-learning ability, innovative spirit and cooperation consciousness.

\section{THE IMPLEMENTATION OF "PROJECT DRIVEN" TEACHING METHOD}

Taking project as guidance, taking the case as the carrier, in the spirit not only to impart knowledge to students, but also to teach students how to learn, to cultivate students' knowledge processing, knowledge conversion ability and analysis, problem solving ability and innovation ability. This has a more stringent requirements for the design of the project.

\section{A. "project" design should be hierarchical}

From the teaching content, the teacher should carefully design each project". Because the "project teaching method" is to allow students to complete the project, at the same time, master knowledge. "Project" has a direct impact on the teaching effect, so the design of the project is very important.

In the design of the project, pay attention to the characteristics of the students and the ability to accept the differences, and take full account of the students' existing foundation, cognitive ability and interest, etc.. In the process of design, from the perspective of students, according to the actual level of the students to design each module, according to different levels of students to design different levels of practice, that is, "project" to have the level of. Start with the simplest of modules to solve practical problems. Through this design, greatly inspired the students' interest and imagination, to the implementation of the differentiated teaching, this chapter of the learning task is also easy to complete.

\section{B. "project" design should have a link Identify the Headings}

"Project driven" teaching at the same time, the curriculum design is also closely integrated into the teaching, in the curriculum design according to the characteristics of the "project", the arrangement of curriculum tasks, inspire students thinking, improve curriculum design. From the point of view of knowledge, the contents of the course are interrelated, and the teacher should help students to make clear the logical connection. In order to help students to achieve the knowledge of the link, in the design of the project, should be appropriate to add some of the "project" and the "sub project" to help students in learning new knowledge at the same time, and timely review has learned knowledge. For example, we can use the expansion module and the integrated module to complete the basic module, not simply repeat. This can cultivate students' divergent thinking and knowledge of the breakthrough.

\section{C. "project" design should be feasible s}

According to the characteristics of the single chip microcomputer course, the experimental teaching content is divided into three parts: basic experiment, basic interface experiment, specific production experiment. 
Basic experiments include hardware, instruction system experiment, assembly language program design experiment. The basic interface experiment includes two parts of hardware connection and software programming. Students in the experiment, first of all, according to the experimental task to complete the hardware design, design of the main circuit, and then write programs, debugging, and finally Proteus, Multisim2000 and other software for simulation. The specific production experiments are completed by the Protel software to complete the printing circuit board, according to the schematic diagram of the circuit board, after the test results, and finally the project requirements, further amendments.

\section{D. "project" design should be participatory}

From the perspective of ability training, teachers should pay attention to mobilize the enthusiasm of the students, cultivate their spirit of innovation and cooperation. In the teaching process, to guide students to participate actively, in order to improve the students' attention in class, so as to improve the learning efficiency. Each project is to enable students to actively participate in, students would be easier to grasp the difficulties, class is not easily distracted, and achieved good teaching effect. By participating in the integration of the relevant knowledge and skills of the organic integration of the project to the project.

In conclusion, we put forward the specific steps are as follows:

1)

roposed tasks (objectives): to propose the course to solve a specific task and requirements.

2)

nalysis tasks (features) : analysis of the method and steps to solve the task, system design.

3)

aster relevant knowledge: explain the necessary support knowledge to achieve this task.

4) implementation plan: according to the requirements of the design scheme, the optimal scheme is selected. Draw circuit diagram, the preparation of the corresponding procedures, simulation, debugging. If the results and the preliminary design of the same, you can buy components, according to the circuit diagram of the circuit board, welding circuit board, debug circuit board. Finally, with the requirements of the project, to further optimize their system to achieve better results.

For example, in the assembly language program design, you can raise questions through a project. The design of program control LED lights on and off. Through the 4 hours of theoretical teaching, and then let the students from two aspects of software and hardware to access information. Software can compare the use of the program in which the statement at least, the most simple programming, hardware, the structure is simple, the lowest cost, and then choose the best software and hardware program to make their own. Students from access to information to the production are completed, the teacher is only playing the role of guidance and question answering. From the traditional teacher's church to the present student's own society's transformation, greatly enhances the student to study the initiative.

\section{ACKNOWLEDGMENT "PROJECT DRIVEN" TEACHING AND CURRICULUM DESIGN, EXPERIMENT AND TRAINING}

In the practical teaching, the "project teaching" is based on the typical technology in practical engineering application, which is based on the typical circuit and realizes the close integration of theoretical teaching, curriculum design, practical teaching and practical teaching. "Project driven" teaching mainly according to the requirements of the project, to explain the idea of the project, the basic hardware structure, instruction system and program design, combined with experimental teaching, in the test box for the verification and simulation, so that students can achieve the basic knowledge and basic skills of SCM, master and application. The course design (Shi Xun) first lets the students complete some basic modules and the design and manufacture of the expansion. And then according to the teacher's practical production and life of the quasi engineering application problems, let the students put forward solutions, to carry out the demonstration and parameters calculation, drawing the corresponding principle diagram, etc., list of components, welding circuit board and debug circuit board. Through the design of the main students to use the microcontroller system development process, for the future in the work of the flexible use of a solid foundation.

Vocational education is mainly to cultivate practical ability, and quickly adapt to the front-line technical personnel. The project teaching method is to meet this requirement, after the first training, to learn to teach, emphasis on students' self learning, active participation, from the beginning, from the most basic circuit construction practice, from the necessary software learning, mobilize the initiative, creativity, enthusiasm, etc., in the guidance of teachers, students themselves to find a variety of problem-solving ideas, and then to the actual economic calculation, to find the best path, and self evaluation, they are in the process of training. In particular, the "single chip microcomputer" teaching, design ideas, methods and diversity, different design ideas, the follow-up of all the work are very different, so that not only exercise the students' responsibility in the end and continue to carry out the curiosity, this teaching idea is also the characteristics of Vocational education.

\section{CONCLUSIONS}

Project teaching can help teachers to implement the overall teaching, and promote the reform of teaching and research and the curriculum reform, so as to continuously improve the quality of teaching. In order to train the talents as the guide, to further drive the project teaching smoothly.

\section{REFERENCES}

[1] Li Jianzhong. The principle and application of single chip microcomputer $[\mathrm{M}]$. Xi'an: Xi'an Electronic and Science University press, 2011

[2] He Qiao. Microcontroller principle and application [M]. Beijing: China Railway Ministry press, 2012J. I. S. Jacobs and C. P. Bean, "Fine particles, thin films and exchange anisotropy," in Magnetism, vol. III, G. T. Rado and H. Suhl, Eds. New York: Academic, 1963, pp. 271-350.

[3] Zhang Xutao. The principle and application of single chip microcomputer [M]. Beijing: Beijing Institute of Technology press, 
2011R. Nicole, "Title of paper with only first word capitalized," J. Name Stand. Abbrev., in press.

[4] Guo Tianxiang, editor in chief of.51 C language tutorial [M] Beijing: Electronic Industry Press, 2011.

[5] A Direct Torque Controller for Permanent Magnet Synchronous Motor Drives.IEEE Transactions on Energy Conversion, 1999, $15-20$

[6] Zhao Jianling, editor of the.51 Series MCU development collection [M]. Beijing: Electronic Industry Press, 2012

[7] Yin Yifeng, editor in chief of Liu Longiiang. [M]. Beijing: Beijing Institute of Technology press, 2010.
[8] Design and Implement of Temperature Control System Based on Single Chip Microcontroller [J]: MICROCOMPUTER INFORMATION. 2012, (26).

[9] 51 language of the permanent editor $\mathrm{C}$ language common module and integrated system design $[\mathrm{M}]$. Beijing: Electronic Industry Press, 2008

[10] Collins Sean P, Hinckley William R, Storrow Alan B. Critical review and recommendations for nesiritide use in the emergency department.[J]. The Journal of Emergency Medicine (Philadelphia), $2012,29(3)$ 